\title{
Antinomias e "suturas" epistemológicas entre biológico-social e individual-coletivo no âmbito da epidemiologia social*
}

\section{Antinomies and epistemological "sutures" between the social-biological and the collective-individual within the field of social epidemiology}

\author{
Djalma A. de Melo-Filho
}

Secretaria de Saúde de Pernambuco. Recife, PE - Brasil

\begin{abstract}
Resumo
A complexidade do objeto epidemiológico tem suscitado, ao longo do tempo, discussão sobre alguns elementos que o compõem, assumindo, muitas vezes, a forma de antinomias. Utilizando-se como substrato textos fundamentais, analisaram-se, no âmbito da epidemiologia social, a formulação e a proposta de solução para as antinomias biológico-social e individual-coletivo. Criticou-se a validade teórica das saídas apontadas pelo discurso epidemiológico-social para resolver o "conflito de leis" que permeia o referido objeto. Destacou-se o conceito marxista-helleriano de indivíduo para contribuir com a "sutura" dos três planos da realidade: o universal, o particular e o singular.
\end{abstract}

Epidemiologia. Processo saúde-doença. Sociologia médica.

\begin{abstract}
The complexity of the epidemiological object has provoked discussion of the elements that have constituted it over time sometimes assuming the form of antinomies. By using as substract fundamental texts, the formulation and the proposal for a solution of the antinomies between the social-biological and the collective-individual are been analysed. The validity of the theoretical wasy ahead indicated by the epidemiological discourse for the solution of the conflict of "laws" that surround this object are been criticized. The concept of the individual in Marx and Heller is been used to contribute to the "suturing" of the three strata of reality: the universal, the particular and the singular.
\end{abstract}

Epidemiology. Health-disease process. Sociology, medical.

*Baseado na Dissertação de Mestrado "Contribuição à compreensão e crítica da epidemiologia social", 1994, apresentada à Faculdade de Medicina da Universidade Federal da Bahia.

Correspondência para/Correspondence to: Djalma A. de Melo-Filho - Secretaria de Saúde de Pernambuco. Rua Nunes Machado, 119/603 - Soledade - 50050-590 Recife, PE - Brasil. Fax: (081) 423-8271.

Recebido em 29.8.1995. Reapresentado em 11.1.1996. Aprovado em 16.2.1996. 


\section{INTRODUÇÃO}

Verifica-se, ao longo da história da epidemiologia, o surgimento de alguns problemas teóricos, muitas vezes formulados como antinomias, no sentido etimológico de "conflito de leis"1. Entre eles, sobressaem-se as relações do biológico com o social e as do individual com o coletivo. O objetivo do presente trabalho consiste em analisar tais questões no âmbito da epidemiologia social, movimento emergente em meados da década de 70, onde se destacaram as contribuições dos programas do Centro de Estudios y Asesoría en Salud - CEAS, no Equador, e da División de Ciencias Biológicas y de la Salud, Universidad Autónoma Metropolitana, Unidad Xochimilco, no México, e de alguns centros de pós-graduação no Brasil ${ }^{2,6,22}$.

Antes de prosseguir, é necessário, todavia, dizer que o uso do termo "epidemiologia social" não goza de unanimidade. Por outro lado, Breilh" considera essa denominação inadequada, pois desconhece uma epidemiologia que não seja social, preferindo, assim, como Almeida Filho², a designação "epidemiologia crítica".

Apesar de concordar com as ponderações, partese da premissa de que há diferenciação entre a epidemiologia crítica e a epidemiologia social. Esta última, além de ser considerada um subconjunto daquela, fez uma recepção completa ou quase completa da filosofia marxista.

Esse tipo de objetivação incita o receptor não só a refletir sobre o modo como se deve pensar, mas também como se deve agir e como se deve viver ${ }^{13}$, característica que não pode ser extensa a todos os sujeitos filiados à epidemiologia crítica onde somente ocorreria uma recepção parcial do marxismo, principalmente daquele momento ligado ao "como se deve pensar", sem guiar necessariamente o agir imediato e a forma de vida ${ }^{13}$.

Como exigência metodológica, é importante ressaltar que o material utilizado para analisar as antinomias, haja vista o pioneirismo e o desenvolvimento de um arcabouço teórico-metodológico compatível com a nova proposta, restringe-se às contribuições de Breilh e Granda ${ }^{7}$ e de Laurell ${ }^{17,18,19}$, que forjaram a epidemiologia social, e, haja vista a importância de suas reflexões para o desenvolvimento geral da teoria epidemiológica, de Almeida-Filho ${ }^{2,3,4}$, autor identificado com a epidemiologia crítica.

\section{A ANTINOMIA BIOLÓGICO VERSUS SOCIAL}

A preocupação com a antinomia "biológico versus social" se encontra presente, logo nos seus primeiros escritos em Laurell ${ }^{19}$. Ao defender uma nova abordagem para a compreensão da saúde-doença, Laurell ${ }^{17}$ diz ser necessário expor as relações entre o biológico e o social deste processo. Em seu texto "A saúde-doença como processo social", Laurell ${ }^{19}$ adota uma posição marcadamente ambígüa sobre as referidas associações. Por um lado, dirime, e nisto concorda-se com a autora, a antinomia, como se pode observar neste trecho: “... o processo saúdedoença do grupo adquire historicidade porque está socialmente determinado. (...) É social na medida em que não é possível focalizar a normalidade biológica do homem à margem do momento histórico. (...). O caráter simultaneamente social e biológico do processo saúde-doença não é contraditório, porém unicamente assinala que pode ser analisado com metodologia social e biológica, ocorrendo, na realidade, como um processo único" 19 .

Não obstante, em outros lugares do referido texto, Laurell abandona a dialética e passa a procurar, de modo altamente formal, uma "ponte" que supostamente existe entre o biológico e o social. Embora recuse, por "biologizar a sociedade", a solução apresentada por Cassel (citado por Laurell ${ }^{19}$ ), que defende o estresse como a única mediação entre os dois pólos, ela torna ontológica a intercessão a tal ponto que deseja de modo teoricamente incorreto "visualizá-la". No excerto a seguir, encontram-se alguns elementos que corroboram com a crítica aqui esboçada. "A evidência empírica (...) permite-nos demonstrar que existe uma relação entre o processo social e o processo saúde-doença. Sem dúvida, esta observação, por si mesma, não resolve qual é o caráter desta relação. Isto porque temos, por um lado, o processo social e, por outro, o processo biológico, sem que seja imediatamente visível como um se transforma no outro. Na verdade, enfrentamos uma "caixa negra", na qual o social entra de um lado e o biológico sai de outro, sem que se saiba o que ocorre dentro dela. Esse é, talvez, o problema mais candente para a explicação causal social do processo saúde-doença. Este problema não está resolvido" 19 .

O mecanicismo como foi estruturada a antinomia salta aos olhos. Considerando que somos um ser social (e não um ser simplesmente que se encontra em sociedade), o problema, formulado dessa maneira, nunca se solucionaria: ao contrário da caixa de Pandora, não há nada de substancial escondido na referida "caixa negra", somente "ecos" revestidos de uma explicação assaz óbvia: "o vínculo entre o processo social e o processo biológico saúde-doença é dado por processos particulares, que são ao mesmo tempo sociais e biológicos"19. 
Em vez de solucionar a antinomia, o que ocorre, na realidade, é uma acentuação do conflito. Quando propõe, em sua teoria, a existência de três níveis, que em nada se assemelham ao que trata a tradicional discussão filosófica sobre o singular, o particular e o universal, para apreender o processo saúde-doença em sua totalidade, Laurell ${ }^{17}$ insere o biológico nos dois primeiros e o social no terceiro. Embora diga que os dois primeiros estejam incluídos no nível social, a formulação não deixa de ser dicotômica: "Um primeiro nível representa um efeito, a enfermidade enquanto processo biológico do indivíduo. O segundo nível constitui a enfermidade como o resultado da interação entre três fatores biológicos: o hospedeiro, o agente e o ambiente, cada um com seus mecanismos dinâmicos de adaptação. Finalmente temos o nível no qual a saúde-enfermidade se apresenta como um fenômeno social e coletivo" ${ }^{17}$.

É oportuno salientar que, em obra mais recente, Laurell ${ }^{18}$ abandona o mecanicismo da "caixa negra" e propõe outra teoria, através do "nexo biopsíquico", para resolver a antinomia. Esse vínculo não estaria localizado no indivíduo, mas sim na coletividade, dessa forma o biológico encontra-se subsumido no social, concepção muito próxima da breilhiana.

Não descartando a contribuição da experiência biológica acumulada, Breilh ${ }^{9}$ a destaca na definição genotípica dos indivíduos e sua respectiva expressão fenotípica em um dado momento histórico. "Com efeito", diz ele, "pelo fato de leis econômicas, políticas e culturais atuarem na base do movimento epidemiológico, isto não quer dizer que não exista espaço para o individual-biológico definir, como parte decisiva, sua realidade. Por conseguinte, embora os processos da natureza, onde se desenvolve a vida de uma população, e os processos biológicos (fisiopatológicos e etiopatogênicos), que ocorrem nos organismos-atores da vida social, subordinem-se aos processos da vida social mais ampla, integrando-os, ambos participam também como determinantes desta vida e como condições decisivas do comportamento epidemiológico. Essa forma de entender a relação entre o social mais geral e o biológico rompe com a idéia de que há uma separação entre essas duas instâncias como a que existiria entre duas partes distintas do mundo, que só se tocassem externamente. Pelo contrário, entre o social mais amplo e o biológico há um profundo entrelaçamento".

Apesar de expor, nesse caso, uma concepção mais dialética do que a primeira formulação laurelliana (caixa negra), a proposta de Breilh ${ }^{9}$ não está isenta de críticas, todavia, elas serão consideradas, em conjunto, quando se analisar a sua con- tribuição para solucionar a antinomia "individual versus coletivo".

Na realidade, a epidemiologia social alimenta um debate que, no meio das ciências sociais, há muito tempo, já se encontra superado. Mesmo "naturalizando" os métodos de abordagem da sociedade, considerando-a até como uma espécie de organismo, os próprios positivistas, inclusive na própria origem da ciência sociológica, procuraram destinar o biológico ou o psicológico, que estariam, de alguma forma, também presentes na construção do fato social, para os biólogos e psicólogos. Essa atitude pode ser verificada em "As Regras do Método Sociológico" de Durkheim ${ }^{10}$. Há quase cem anos (1895), quando foram publicadas, a hesitação já havia sido resolvida: uma das regras diz que o fato social é uma coisa, mas todas elas garantem, em tom peremptório, que ele jamais será deduzido dos níveis biológico ou psicológico.

Mesmo estando submetida à clínica a definição de uma de suas partes, o objeto epidemiológico não apresenta, como se acredita, nenhuma peculiaridade em relação a outros objetos científicos. Os geógrafos, rejeitando a concepção que considera o seu objeto de investigação como sendo de "contato" entre a natureza e a sociedade, asseveram que sua ciência não discute os processos naturais em si, isto é, a natureza do homem, e sim a natureza para o homem ${ }^{21}$. O próprio objeto dos sociólogos, que é o fato social, refere-se a seres humanos vivos, lembrando-se, entretanto, que a vida constitui o objeto de estudo de outra ciência - a biologia.

Embora as digressões sobre a interface entre o biológico e o social não ocupam hoje um lugar de destaque dentro de outras ciências sociais, o debate permanece ativo dentro da epidemiologia, principalmente, quando vem à tona a sua relação com a clínica. É como se a epidemiologia, assim como as personagens da tragédia grega, tivesse que expiar para sempre uma culpa por perquirir um objeto que contém o biológico em sua constituição. Se a geografia ou a sociologia, entre outras, também apresentam características similares em seus objetos, por que somente a epidemiologia, ao insistir na procura da inexistente "ponte" ou "caixa negra" entre o biológico e o social, teima em remir a culpa? Certamente, a ela somente interessaria o biológico para o homem, em contraste com o biológico do homem.

Corrigindo uma de suas preocupações anteriores, Almeida-Filho ${ }^{2}$ diz, muito acuradamente, que "um fato biológico em seres humanos é em si social e historicamente determinado. Um projeto científico mais conseqüente não deverá buscar o isolamen- 
to e sim a totalização". Sobre a "interface entre o biológico e o social", ele conclui: "Em minha opinião, esta é uma expressão pedante, de sentido obscuro, que entretanto tornou-se moda no discurso sanitarista das duas últimas décadas"4.

\section{A ANTINOMIA INDIVIDUAL VERSUS COLETIVO}

A fim de continuar a análise das antinomias no âmbito da epidemiologia social, faz-se um necessário interregno para descrever o problema em um autor que se insere na epidemiologia crítica. Ao discutir a teoria do conhecimento epidemiológico, Almeida-Filho ${ }^{3}$ conclui: "O objeto-modelo da epidemiologia constitui-se em um objeto intermediário, que serve a uma função de ligação entre campos do conhecimento em saúde a fim de dar conta da lacuna que existe entre o individual e o coletivo. Tal objetomodelo não se refere essencialmente ao coletivo, simbolizado com que tipicamente tem-se acostumado nas abordagens sociais da saúde, nem relaciona-se com a mera expressão individual, característica da clínica "vulgar'".

Assim como a causalidade metonímica, AlmeidaFilho ${ }^{3}$ propõe para a epidemiologia um objeto-ausente. A metáfora da "lacuna" faz lembrar os comentários de Foucault ${ }^{11}$, considerados geniais por Habermas, sobre o famoso quadro "Las Meninas" do pintor espanhol Diego Velázquez (1599-1660). Atente-se, inicialmente, na medida do que é possível, para a descrição sucinta da pintura, que se encontra no Museu do Prado (Espanha), e para as observações foucaultianas que servem de exórdio para “As Palavras e as Coisas". Posteriormente, à luz de ambas, descrição e observações, tentar-se-á compreender a referida "lacuna".

Ao se buscar, no âmbito da pintura, algo que sintetize, de forma vigorosa, o culto ao contraste, característico da literatura barroca, de onde se sobressaem antíteses, paradoxos e hipérbatos, talvez se encontre em "As Damas de Honor", outra denominação para a mencionada pintura, o que se deseja: o recurso ao espelho maximiza, ao infinito, o efeito de tais figuras.

Em uma primeira aproximação, o quadro retrata, possivelmente, o ateliê do próprio pintor, situado no palácio real. Tomando-se como referência a posição de um espectador, pode-se observar em seu centro a infanta Margarida e suas damas de companhia. À direita, encontram-se dois bufões da corte: a anã macrocéfala Maribarbola e o anão Nicolaso Pertusato que pisa num cachorro que está estirado no chão.
Num segundo plano, ainda à direita, estão outra dama de companhia e um homem; no fundo do ambiente, acha-se Nieto, o chefe das tapeçarias do rei.

Não obstante se reconheça a importância estética do centro e da parte direita da pintura, os comentários mais interessantes provêm da observação do lado esquerdo. Encontra-se aí uma enorme tela, sustentada por um cavalete, da qual só se vê o seu reverso. Ao lado dela, num momento de pausa em sua atividade, perfila-se, auto-retratado, com o pincel e palheta na mão, o próprio pintor Velázquez que, ao lançar seu olhar para frente, provoca uma estranha sensação, fazendo com que o próprio espectador se sinta como sendo o objeto a retratar. O jogo ilusório é tão perfeito que, em 1819, ao ver "Las Meninas", o poeta francês Théophile Gautier indaga: "Mas onde está o quadro?"11, 12,16.

Foucault assinala essa reciprocidade: "olhamos um quadro de onde um pintor, por sua vez, nos contempla. (...) O pintor só dirige os olhos para nós na medida em que nos encontramos no lugar do seu motivo. Nós, espectadores, estamos em excesso. Acolhidos sob esse olhar, somos por ele expulsos, substituídos por aquilo que desde sempre se encontrava lá, antes de nós: o próprio modelo". Um espelho que se encontra dependurado na parede do fundo do ambiente de trabalho do artista esclarece o enigma: o que, possivelmente, se encontra retratado na parte dianteira da "outra" tela é o casal real, Filipe IV e Mariana, que posa (o espaço onde ele estaria realmente também se acha oculto) para Velázquez e, dessa forma, tem a sua imagem captada pelo referido espelho.

Finalmente, onde reside a imagem que poderá contribuir para o enriquecimento da reflexão que foi temporariamente suspensa? Recorde-se, pois, que o objeto-modelo, proposto por Almeida-Filho ${ }^{3}$ para a epidemiologia, não se encontra nem no coletivo, nem tampouco no individual. Essa "ausência" remete-se ao triângulo virtual, apreendido por Foucault ${ }^{11}$, onde "os olhos do pintor" ocupam o vértice superior, "o lugar invisível do modelo" insere-se em um dos vértices da base e no outro, aparece "a figura provavelmente esboçada na tela virada".

O objeto epidemiológico, assim como aquele que é mostrado no espelho do quadro pintado em 1656, surge como "um reflexo tão longínquo, tão imerso num espaço irreal, tão estranho a todos os olhares que se voltam para outras partes, que não é mais do que a mais frágil reduplicação da representação" ${ }^{11}$. A analogia sugere que o objeto "doentes em população" cujo núcleo seria constituído pelo objeto clínico e a "casca", pelo objeto das ciências sociais visaria a um es- 
paço lacunar supostamente existente entre o individual e o coletivo, ou seja, assumiria uma função de "ponte" entre a clínica e as ciências sociais".

O recurso à metáfora da "lacuna" será aqui recusado. Por um lado, ele é criticado por Foucault ${ }^{11}$ no próprio âmbito estruturalista: "Ademais, essa ausência não é uma lacuna, salvo para o discurso que laboriosamente decompõe o quadro, pois ela não cessa jamais de ser habitada e de ser realmente, como o provam a atenção do pintor representado, o respeito das personagens que o quadro figura, a presença da grande tela vista ao revés e nosso próprio olhar para quem esse quadro existe e para quem, do fundo do tempo, ele foi disposto".

Por outro, numa perspectiva marxista, sublinhase que a antinomia "individual versus coletivo" também não se acha adequadamente formulada. Marx ${ }^{20}$ diz que "O homem - por mais que seja um indivíduo particular, e justamente é sua particularidade que faz dele um indivíduo e um ser social individual efetivo - é, a mesma medida, a totalidade, totalidade ideal, o modo de existência subjetivo da sociedade pensada e sentida para si, do mesmo modo que também na efetividade ele existe tanto como intuição e gozo efetivo do modo de existência social, quanto como uma totalidade de exteriorização da vida humana".

Após a digressão no campo da epidemiologia crítica, retome-se o âmbito mais restrito da epidemiologia social. A proposta de Laurell ${ }^{19}$ insere, timidamente, a problemática do singular, do particular e do universal ou geral em sua reflexão sobre o objeto de estudo e a determinação em epidemiologia. Remetendo-se àquele, Laurell ${ }^{19}$ argumenta: "O primeiro elemento que deveria ser reconhecido é que o caráter social do processo saúde-doença manifesta-se empiricamente mais claro a nível da coletividade que do indivíduo (...) Isto mostra que nosso objeto de estudo não se situa a nível do indivíduo e sim do grupo".

A particularidade, âmbito do objeto epidemiológico, é assim concebida: "A relação entre o processo de saúde-doença coletiva e o do indivíduo fica, então, estabelecida, porque o processo saúdedoença coletiva determina as características básicas sobre as quais assenta-se a variação biológica individual. Visto isto a partir do paciente significa que sua história social assume importância, porque condiciona sua biologia e determina certa probabilidade de que adoeça de um modo particular, porém, como sabemos, a probabilidade não se efetiva no indivíduo, senão como presença ou ausência do fenômeno"19.
Sobre a singularidade, Laurell ${ }^{19}$ afirma que " $a$ investigação do padrão de desgaste e do perfil patológico tem que ser feita relativamente aos organismos dos membros do grupo pesquisado não com a singularidade de cada caso individual, como é feito pela medicina clínica, mas estabelecendo-se o comum, isto é, que caracteriza o grupo".

Finalmente, ao discutir a determinação, Laurell ${ }^{19}$ remete-se à dimensão do universal: "Em termos muito gerais, o processo saúde-doença é determinado pelo modo como o homem se apropria da natureza em um dado momento, apropriação que se realiza por meio do processo de trabalho baseado em determinado desenvolvimento das forças produtivas e relações sociais de produção".

Verifica-se na proposta laurelliana uma sistematização dos níveis de apreensão do real, contudo o desenvolvimento de sua contribuição não problematiza, de modo satisfatório, a mediação entre os três planos.

Ao formular a antinomia individual versus coletivo de maneira diferente daquelas já mencionadas, Breilh ${ }^{9}$ consegue dar um passo à frente na discussão, embora não se concorde teoricamente, como se verá mais adiante, com o seu produto final. Não obstante, se considere a relação como um falso conflito, ele caminha em sua argumentação a fim de superá-lo. Em vez de "individual versus coletivo", a questão, agora posta, seria entre "o geral e o individual" .

A proposta breilhiana destaca os componentes de cada um dos níveis constituintes da realidade. O primeiro deles, o universal, também chamado de geral, é formado pelos processos estruturais que se encontram na base do desenvolvimento social e rege-se fundamentalmente pelas leis dialéticas e causais. $\mathrm{O}$ segundo, o particular, onde operam não só as leis anteriores, mas também as leis funcionais, compreende o processo de reprodução social, caracterizado pela produção e consumo de cada grupo socioeconômico. O terceiro, que seria o singular, é denominado, de forma teoricamente não adequada, de individual, sendo formado pelos processos responsáveis, de um modo mais imediato, pelo adoecer-morrer ou pela manutenção da saúde, nele operam principalmente as leis funcionais e as leis estatísticas $^{7,8}$.

Segundo Breilh ${ }^{9}$, os três planos, formadores do "universo", estabelecem entre si relações invariáveis que possuem status de leis. A fim de superar a "velha e restrita noção epidemiológica de causa", que busca explicar as referidas relações unicamente através de seu componente eficiente, ele toma emprestado da teoria bungiana do conhecimento um elenco 
de categorias de determinação, onde são referenciadas as quatro principais: "a) determinação dialética da totalidade do processo pela luta interna e pela eventual síntese subseqüente de seus componentes essenciais opostos; $b$ ) determinação causal ou causação: determinação do efeito pela causa eficiente (externa); c) interação (ou causação recíproca ou interdependência funcional): determinação do conseqüente pela ação recíproca; d) determinação probabilística: do resultado final, pela ação conjunta de entidades independentes ou semi-independentes".

Apesar de afirmar sua adesão ao materialismo histórico-dialético, quando procura analisar as relações entre o individual e o coletivo, Breilh ${ }^{8}$ não consegue se livrar do estrutural-funcionalismo. A fim de tentar explicar que o individual e o biológico encontram-se subsumidos no social, comporta-se como um autêntico durkheimiano: “... mas uma vez que o todo social compõe-se de partes que podemos descrever e medir empiricamente, compreende que a participação dessas partes no todo gera uma realidade complexa, superior, com qualidades diferentes às das partes, ainda que seja dependente destas para a sua existência. O pensamento científico, dessa forma, não só consegue explicar a unidade da realidade, mas também traduz as relações necessárias e hierárquicas entre os processos que a constituem".

O "qualitativamente diferente" e a "relativa dependência do todo em relação às partes" encontramse também mencionados em "As regras do método sociológico". Nelas, Durkheim ${ }^{10}$ assevera que cabe ao teórico da nova ciência, a sociologia, expor argumentos que possam convencer o meio científico da existência de um objeto qualitativamente novo, não redutível ao somatório de quantidades diversas, característico daquele reivindicado pela psicologia: "Um todo não é idêntico à soma das partes que o constituem; é algo de diferente cujas propriedades diferem das que revelam as partes de que é composto"10. Tal postulado, em linguagem sociológica, poderia assumir a seguinte redação: "a sociedade não é uma simples soma de indivíduos, pois o sistema formado pela associação destes representa uma realidade específica que tem as suas características próprias. Sem dúvida que nada se pode produzir de coletivo sem que se manifestem consciências particulares; mas esta condição necessária não é suficiente"10.

Em relação ao par "todo versus parte", tradicionalmente identificado com o estrutural-funcionalismo, o discurso breilhiano, talvez, registre uma de suas maiores ambigüidades ou, mesmo, contradições. Aqui se refere precisamente às relações de dependência estabelecidas entre os dois planos. Breilh ${ }^{9}$ afirma que o todo, embora seja qualitativamente diverso, depende das partes para existir, entretanto no excerto a seguir, ele, mais uma vez durkheimiano, argumenta: "a epidemiologia científica estabelece que a realidade social não é a soma do que se observa nos indivíduos e se relaciona estatisticamente, mas que, na realidade, os processos individuais entrecruzam-se e surgem como resultantes das forças econômicas, políticas e culturais que operam como um todo, acima das circunstâncias e vontades individuais".

Embora cem anos os separem, há uma proximidade semântica entre o trecho acima e este, advindo da receita durkheimiana: "As causas geradoras das representações, das emoções, das tendências coletivas não são constituídas por certos estados da consciência dos particulares, mas pelas condições em que se encontra o corpo social tomado em conjunto. É claro que só se podem realizar se as naturezas individuais não se revelarem refratárias a este; mas estas constituem apenas a matéria indeterminada que o fator social determina e transforma. A sua contribuição limita-se aos estados muito gerais, às predisposições vagas e, por conseguinte, plásticas que não conseguiriam, por si sós, tomar as formas definidas e complexas que caracterizam os fenômenos sociais"10.

Sem dúvida, Breilh" recusaria a expressão "matéria indeterminada", pois, para ele, "as condições e possibilidades individuais fundem-se num todo social, numa média geral ou resultante comum, que não anula a participação do individual, já que os contingentes dos indivíduos contribuem para esse resultante". Ao afirmar que dessa forma teria dissipado a "falsa relação entre o 'geral' e o 'individual", ele novamente cria uma outra falsa oposição quando acredita que o todo age "acima das circunstâncias e vontades individuais".

Breilh ${ }^{9}$ situa o indivíduo no plano singular e diz que a vida cotidiana encontra-se também nessa dimensão. Como consequiência dessa posição, tanto o particular quanto o universal (geral) serão cada vez mais reificados. Até encontrar, em "O Capital", um "Marx claramente epidemiológico", Breilh" irá destacar citações de obras anteriores, inclusive dos "Manuscritos", para que possam contribuir com a tarefa de uma "reinterpretação científica do processo saúde-doença". Apesar de haver consultado os "Manuscritos econômico-filosóficos" do jovem Marx ${ }^{20}$, não sublinha este famoso excerto: "Deve-se evitar antes de tudo fixar a 'sociedade' como outra abstração frente ao indivíduo. O indivíduo é o ser social. A exteriorização da sua vida - ainda que não apareça na forma imediata de uma exteriorização de vida 
coletiva, cumprida em união e ao mesmo tempo com outros - é, pois, uma exteriorização e confirmação da vida social. A vida individual e a vida genérica do homem não são distintas, por mais que, necessariamente, o modo de existência da vida individual seja um modo mais particular ou mais geral da vida genérica, ou quanto mais a vida genérica seja uma vida individual mais particular ou geral".

As reflexões do jovem Marx, ainda, como diria Althusser ${ }^{5}$, "contaminado" pelo hegelianismo, traduzem, de maneira dialética, as relações entre indivíduo e sociedade, não permitindo, todavia, que esta "engula" aquele, como poderão fazer crer suas obras mais tardias. Acredita-se não ter sido casual a inexistência dessa citação em Breilh ${ }^{9}$, principalmente, no momento, em que descreve, em sua obra principal, as "leis" de cada um dos níveis assinalados acima. Apesar de criticar Althusser, a desconsideração do fragmento citado coloca Breilh no mesmo âmbito daqueles que se utilizam de um "bisturi" a fim de extirpar o que há de hegeliano na obra do autor de "O Capital", separando, finalmente, um Marx ideológico de um Marx científico. Como se sabe, Althusser ${ }^{5}$ recusou totalmente o Marx anterior a 1845 (ano da cesura) ele afirma que o texto dos "Manuscritos econômico-filosóficos", de 1844, produzido na "quase última noite é paradoxalmente o texto mais distanciado que há, teoricamente falando, do dia que ia nascer". A crítica de Breilh ${ }^{9}$ ao pensador do estruturalismo francês, mesmo recusado a truculência do "bisturi", não o impede de fazer, pelo menos, uma "leitura seletiva" de onde emerge somente um Marx científico que iria iluminar a "epidemiologia científica" contraposta à "ideologia epidemiológica".

A fim de promover a passagem do "concretodescritivo" para o "concreto-racional", Breilh" remete-se a Marx, já "científico", de "Para a Crítica da Economia Política": "Do ponto de vista lógico, o ponto de partida é a representação do objeto, o que em epidemiologia seria a representação do fenômeno epidemiológico em suas manifestações externas, processo que está sempre condicionado pela nossa prática social. O que se procura é desvendar as formas de antagonismos inerentes ao mesmo objeto. Podemos, evidentemente, construir o nosso concreto-descritivo à base de fontes diretas e indiretas. À medida que avança a prática social que nos une ao objeto de investigação, podemos identificar os pontos nodais da problemática e priorizar certos processos e relações, com a finalidade de efetuar uma análise mais profunda. Deste modo chegamos analiticamente a categorias cada vez mais simples e abstratas, conseguindo delimitar os processos que constituem as diferentes dimensões de nosso objeto de estudo (gerais, particulares e singulares ou individuais)"

Mesmo fazendo alusão à obra helleriana, ao enquadrar a vida cotidiana no âmbito do singular, Breilh ${ }^{9}$ não consegue se desfazer de uma "confusão" na definição das categorias indivíduo e homem-particular. Embora se considere a máxima helleriana de que "toda compreensão envolve um mal-entendido", acredita-se, todavia, que a leitura de sua "Sociologia da vida cotidiana" dificilmente permite tratar as referidas categorias como semelhantes. Logo na abertura da referida obra, a pensadora húngara define o que é vida cotidiana: "o conjunto de atividades que caracterizam a reprodução dos homens particulares, os quais, por sua vez, criam a possibilidade da reprodução social", conseqüentemente, o seu plano é a particularidade e não, somente, a singularidade. Mesmo sabendo-se que para se tornar indivíduo seja necessário ser antes um homem-particular, de tal afirmação não se pode deduzir que todo homem-particular constitua também um indivíduo.

Heller $^{14}$, a partir de Marx, de forma clara e precisa, faz a diferenciação entre ambos. O homem-particular está circunscrito à sua particularidade; o indivíduo é justamente o ser que se eleva acima dessa dimensão. O indivíduo é "o oposto da pessoa particularista", ele é "um membro da humanidade que tem uma relação consciente com a espécie". Mesmo em épocas, como a atual, caracterizadas por intensa alienação, o homem-particular pode-se dirigir para a genericidade: "Nada está isento de motivações particulares, mas não existe nenhum homemparticular que não se tenha elevado, mais ou menos, de algum modo, por cima de sua própria particularidade. Por isso não é possível separar rigidamente o homem-particular do homem individual" ${ }^{15}$. O indivíduo é um valor, e não uma coisa, que se relaciona com a "essência humana", formada, segundo Marx, pelo trabalho, sociabilidade, consciência, universalidade e liberdade, sendo a própria história um processo onde tais potencialidades poderão ser desenvolvidas. Ele é devenir, embora não significa que haja uma "necessidade histórica" ou mesmo uma "necessidade natural" que lhe garanta seu desenvolvimento, existem somente possibilidades: "Foi só na época presente (quero com isto dizer, a época do próprio Marx e os anos que lhe seguiram) que se verificaram essas condições econômicas que permitiriam ao homem superar a alienação e que tornariam possível ao indivíduo adquirir e realizar a riqueza da espécie" 14 . 


\section{CONSIDERAÇÕES FINAIS}

A fim de elaborar uma síntese final para a questão das antinomias, convém, de modo breve, recordar a formulação e, conseqüentemente, a proposta teórica para solucioná-la. Inicialmente, analisou-se, em Laurell e em Breilh, a tensão existente entre o biológico e o social. Constatou-se que a versão laurelliana, relativa à metáfora da "caixa negra" onde "o social entra de um lado e o biológico sai de outro", era excessivamente mecanicista: a "caixa", na verdade, estaria ocupando o lugar da "máquina" e o uso do adjetivo "negra" visaria ao obscurecimento da "sutura" cuja investigação, no campo científico, já dura pelo menos cem anos. Aqui, pareceu estar havendo uma tentativa de solucionar um problema, construído à maneira kantiana (a coisa em-si estaria contida na "caixa"?), utilizando-se a teoria marxista que pressupõe a possibilidade do conhecimento da essência dos fatos.

Verificou-se, por outro lado, no discurso breilhiano, uma abordagem mais dialética da questão, onde o biológico estaria subsumido no social, contudo, duvidou-se da pertinência, nos referidos termos, do prolongamento do debate sobre a antinomia no âmbito da epidemiologia. Ao encerrar as digressões sobre a referida antinomia, concordouse com Almeida-Filho quando afirma, ratificando o que diz a ciência moderna, que um fato biológico humano é simultaneamente social e historicamente determinado.

A crítica de Almeida-Filho à formulação antinômica "biológico versus social" vem acompanhada, como se viu, de um novo par colidente: "individual versus coletivo". O objeto epidemiológico, segundo o referido autor, serviria de elo de ligação entre campos de conhecimento em saúde, possibilitando uma maior integração entre o individual e o coletivo. Ao invés da "caixa negra", surgiria no local uma "lacuna" a ser ocupada por um objeto-ausente. Todavia, a partir de Foucault e Marx, argumentou-se contra a existência da referida "lacuna".

A proposta de Laurell utiliza a mesma formulação de Almeida-Filho, contudo acrescenta, de modo

\section{REFERÊNCIAS BIBLIOGRÁFICAS}

1. ABBAGNANO, N. Dicionário de filosofia. $2^{2}$ ed. São Paulo, Ed. Mestre Jou, 1982.

2. ALMEIDA-FILHO, N. Epidemiologia sem números: uma introdução crítica à ciência epidemiológica. Rio de Janeiro, Ed. Campus, 1989. superficial, a problemática do singular, do particular e do universal. Breilh, como se pôde constatar, é quem vai aprofundar essa discussão, embora ainda formule a antinomia de modo teoricamente inadequado: "individual versus geral". Ao utilizar um conceito não marxista de indivíduo, Breilh o insere no nível singular ou o confunde com homem-particular cujo âmbito de pertinência é a particularidade, não solucionado, conseqüentemente, a antinomia.

Ao se rejeitarem todas as formulações expressas pela epidemiologia social, tal como foi definida no presente trabalho, e aquela proposta por AlmeidaFilho, no âmbito da epidemiologia crítica, não se pretende procurar o elo de ligação entre o biológico e o social, ou entre o individual e o coletivo, ou, tampouco, entre o individual e o geral; na realidade, busca-se, agora, o elemento que uniria o singular, o particular e o universal.

À luz de Marx e de Heller, o elo de ligação seria o próprio indivíduo o ser que "transfixa" o singular, o particular e o universal. Convém sublinhar que a concepção helleriana de indivíduo não se encontra próxima do que consigna vulgarmente o liberalismo. Pelo contrário, segundo Heller ${ }^{15}$, "um indivíduo é um homem que se encontra em relação consciente com a genericidade e que ordena sua vida cotidiana com base também nesta relação consciente - evidentemente no seio das condições e possibilidades dadas. O indivíduo é um singular que sintetiza em si a unicidade acidental da particularidade e a universalidade da genericidade".

Trazendo a reflexão para o objeto epidemiológico, o processo saúde-doença em populações, podese dizer que, por um lado, caberia à epidemiologia explicar e compreender quais seriam as causas das doenças ou agravos que diminuem a quantidade de anos vividos. Nesse caso, somente o aspecto quantitativo da questão seria alcançado, pois a investigação visaria apenas ao homem-particular e à reprodução da vida cotidiana. Por outro lado, é necessário também que se aspire à apreensão de uma substância diferente, o indivíduo, onde seriam perscrutadas as causas das doenças e agravos que comprometem a qualidade de vida.

3. ALMEIDA-FILHO, N. O problema do objeto de conhecimento na epidemiologia. In: Costa, D. C., org. Epidemiologia: teoria e objeto. São Paulo, Ed. Hucitec, 1992. p. 203-20.

4. ALMEIDA-FILHO, N. Um objeto-resíduo (e seus limites). In: Almeida-Filho, N. A clínica e a epidemiologia. Salvador, Ed. Apce, 1992. p. 46-61. 
5. ALTHUSSER, L. A favor de Marx. $2^{\underline{a}}$ ed. Rio de Janeiro, Ed. Zahar, 1979.

6. BARRETO, M. L. A epidemiologia, sua história e crises: notas para pensar o futuro. In: Costa, D. C., org. Epidemiologia: teoria e objeto. São Paulo, Ed. Hucitec, 1990. p. 19-38.

7. BREILH, J. \& GRANDA, E. Investigação da saúde na sociedade: guia pedagógico sobre um novo enfoque do método epidemiológico. São Paulo, Ed. Instituto de Saúde, 1986.

8. BREILH, J. Epidemiologia: economia, medicina y política. México, Ed. Fontamara, 1986.

9. BREILH, J. Epidemiologia: economia, política e saúde. São Paulo, Ed. Unesp/Hucitec, 1991.

10. DURKHEIM, E. As regras do método sociológico. São Paulo, Ed. Abril Cultural, 1978.

11. FOUCAULT, M. As palavras e as coisas: uma arqueologia das ciências humanas. 5ª ed. São Paulo, Ed. Martins Fontes, 1990.

12. GÊNIOS DA PINTURA (maneiristas e barrocos). São Paulo, Ed. Abril Cultural, 1980.

13. HELLER, A. A filosofia radical. São Paulo, Ed. Brasiliense, 1983.
14. HELLER, A. Sobre os instintos. Lisboa, Ed. Presença, 1983.

15. HELLER, A. Sociología de la vida cotidiana. $3^{\underline{a}} \mathrm{ed}$. Barcelona, Ed. Península, 1991.

16. JABOR, A. Em As Meninas Velázquez pinta o espectador. In: Jabor, A. Os canibais estão na sala de jantar. $4^{a}$ ed. São Paulo, Ed. Siciliano, 1993. p. 153-6.

17. LAURELL, A. C. Algunos problemas teoricos y conceptuales de la epidemiologia social. Rev. Centroamer. Cienc. Salud, 6:79-87, 1977.

18. LAURELL, A. C. \& NORIEGA, M. Processo de produção e saúde: trabalho e desgaste operário. São Paulo, Ed. Hucitec, 1989.

19. LAURELL, A. C. A saúde-doença como processo social. In: Nunes, E. D., org. Medicina social: aspectos históricos e teóricos. São Paulo, Ed. Global, 1983. p. 133-58.

20. MARX, K. Manuscritos econômico-filosóficos: terceiro manuscrito. $5^{\mathrm{a}}$ ed. São Paulo, Ed. Nova Cultural, 1991.

21. MORAES, A. C. R. \& COSTA, W. M. Geografia crítica: a valorização do espaço. $2^{\text {a }}$ ed. São Paulo, Ed. Hucitec, 1987.

22. ROMERO, A. El desarrollo historico de la epidemiologia en America Latina. In: Congresso Brasileiro de Epidemiologia, 1ํㅡ, Campinas, 1990. Anais. Campinas Abrasco, 1990. p. 81107. 